\title{
Efeitos quantitativos da estocagem de sangue periférico nas determinações do hemograma automatizado
}

\author{
Storage effects on peripheral blood samples as identified from automated hemograms
}

\author{
Michele Dalanhol \\ Morgana Barros ${ }^{2}$ \\ Josmar Mazuchelli ${ }^{3}$ \\ Paulo Henrique Silva ${ }^{4}$ \\ Yoshio Hashimoto ${ }^{4}$ \\ Álvaro Largura ${ }^{5}$
}

\begin{abstract}
O presente trabalho avaliou as possiveis alterações em vários parâmetros do hemograma (contagem de eritrócitos totais, hematócrito, concentração de hemoglobina, volume corpuscular médio (VCM), hemoglobina corpuscular média (HCM), concentração da hemoglobina corpuscular média (CHCM), contagem total de leucócitos e contagem de plaquetas), frente a diferentes tempos de armazenamento da amostra em ambiente refrigerado a $4^{\circ} \mathrm{C}$ e temperatura ambiente. As determinações foram realizadas através do contador automatizado Sysmex ${ }^{\circledR} X T 2000 i$. As amostras sanguíneas foram obtidas de indivíduos sem alterações hematológicas diagnosticadas, sem clínica de doença, sendo considerados individuos com valores de referências hematológicos normais. Os resultados foram avaliados através de análise estatística descritiva e comparação de médias através da análise de variância (ANOVA). Os resultados dos parâmetros $C H C M$ e contagem de plaquetas mostraram diferenças estatisticamente significativas para ambas as temperaturas de estocagem. Na temperatura ambiente, os parâmetros que também apresentaram diferença estatística significante foram para o hematócrito, VCM e indice de variação do tamanho dos eritrócitos $(R D W)$. Conclui-se, portanto, que os resultados dos hemogramas liberados pelo aparelho analisado podem ser satisfatórios quando realizados entre 12 a 24 horas após a coleta da amostra para a maioria dos parâmetros avaliados. Rev. Bras. Hematol. Hemoter.
\end{abstract}

Palavras-chave: Sangue; contagem de células sanguíneas; armazenamento de materiais de provisões; equipamento; parâmetros.

\section{Introdução}

O hemograma proporciona avaliação dos três componentes principais do sangue periférico (eritrócitos, leucócitos e plaquetas) e, portanto, é a base de qualquer avaliação hematológica. O processo de realização do hemograma envolve quatro etapas; a) coleta e processamento da amostra de sangue periférico; b) contagem das células, incluindo determinações dos índices da série vermelha; c) determinação diferencial dos leucócitos, e d) microscopia do esfregaço de sangue periférico para avaliação de potenciais anormalidades morfológicas. ${ }^{1} \mathrm{Na}$ investigação de funções e disfunções do sangue, é fundamental que, dentro do possível, testes laboratoriais não forneçam informações enganadoras devido a erros técnicos; por isso é importante evitar erros na coleta, armazenamento e transporte das amostras ao laboratório. ${ }^{2}$

\footnotetext{
${ }_{2}^{1}$ Farmacêtica bioquímica. Setor de Hematologia e Citometria de Fluxo do Laboratório Álvaro, Cascavel-PR.

${ }^{2}$ Farmacêutica bioquímica. Professora colaboradora do curso de Farmácia, Universidade Estadual do Oeste do Paraná, Centro de Ciências

${ }_{3}$ Médicas e Farmacêuticas, Laboratório de Hematologia Clínica.

${ }^{3}$ Professor de Estatística da Universidade Estadual de Maringá - UEM - Maringá-PR..

${ }_{5}^{4}$ Farmacêutico bioquímico. Professor do curso de Especialização em Hematologia Laboratorial - SBAC - Curitiba-PR

${ }^{5}$ Farmacêutico bioquímico. Centro de Análises e Pesquisas Clínicas - DASA - Cascavel-PR; Instituto de Investigação Científica do Paraná.
}

Sociedade Brasileira de Análises Clínicas - SBAC - PR.

Correspondência: Michele Dalanhol

Rua General Osório, 3212, Centro

85801-110 - Cascavel-PR - Brasil

Tel.: (55 45) 3220-8000 ramal 8003

E-mails: hematologia@alvaro.com.br-mdalanhol@yahoo.com.br 
A garantia da qualidade da realização do hemograma automatizado tem como objetivo assegurar a confiabilidade dos testes hematológicos em todas as fases (pré-analítica, analítica e pós-analítica). ${ }^{3,4}$

Com relação aos fatores inerentes ao exame, é recomendado que a amostra seja de punção venosa; o garroteamento deve ser feito de modo rápido, e, de preferência, logo após a punção da veia o garrote seja liberado, não ultrapassando o tempo de um minuto. ${ }^{5}$ A coleta pode ser realizada mediante uso de seringas e agulhas, ou tubos com vácuo, e que, em qualquer modo que for colhido, seja respeitado a correta relação sangue/anticoagulante, sendo o anticoagulante de melhor escolha, EDTA, preferencialmente di ou tripotássico $(1,5 \pm 0,25 \mathrm{mg} / \mathrm{mL}$ de sangue $) .{ }^{2}$ As amostras devem ser homogeneizadas por, no mínimo, cinco inversões, para que não ocorra o aparecimento de microcoágulos, e depois colocadas em agitador mecânico por 2-5 minutos ou invertidos manualmente oito a dez vezes para posterior realização do exame. Em amostras conservadas a $4^{\circ} \mathrm{C}$, o sangue torna-se viscoso, e deve-se permitir que retome à temperatura ambiente antes da homogeneização. ${ }^{1,67,8}$ Quando alguma amostra que estava em repouso, por algum motivo, precisa ser repetida, o tempo de homogeneização deve ser de 15 minutos. ${ }^{5}$

A distenção sanguínea deve ser feita, sempre que possível, antes de três horas, já que, após esse tempo, as alterações podem ser notadas e, após 12 a 18 horas, tornam-se chamativas. ${ }^{2,8,9}$ Laboratórios que recebem amostras transportadas de locais distantes devem estar conscientes das alterações induzidas pela estocagem..$^{2,6}$

A estocagem prolongada de sangue anticoagulado com EDTA causa crenação ou alterações equinocíticas nos eritrócitos, degeneração dos neutrófilos e lobulação de núcleos de linfócitos. O excesso de EDTA pode, por si só, causar crenação nos eritrócitos, acelerando também o desenvolvimento de alterações relacionadas à estocagem. Os neutrófilos em degeneração podem ter aspecto semelhante ao dos neutrófilos necrobióticos formados in vivo, ou podem ser completamente amorfos. Se a amostra de sangue levar muito tempo para chegar ao laboratório, por exemplo, três dias ou mais, a maioria dos neutrófilos terá sofrido degeneração; consequentemente, a contagem leucocitária terá diminuído. ${ }^{6,10,11}$

Se o bioquímico inexperiente não reconhecer o artefato de estocagem e realizar a contagem diferencial, serão registradas neutropenia e linfocitose falsas. Observadores inexperientes podem cometer o erro de classificar os neutrófilos com uma única massa nuclear arredondada como eritrócitos nucleados. A estocagem também leva a alterações artefatuais nas contagens sanguíneas automatizadas. ${ }^{6,11}$

Outra alteração artefatual rara é a produzida pelo aquecimento acidental das amostras, por exemplo, quando são transportados por um veículo quente. Isto causa grosseira fragmentação dos eritrócitos, a qual pode ser confundida com a piropoiquilocitose hereditária. ${ }^{6,8}$
Quando a distensão é considerada adequada para exame, o passo seguinte é avaliar sistematicamente todos os tipos de células e também a coloração de fundo. Devem ser comparados os achados com as contagens eletrônicas, para decidir se a contagem de leucócitos, a hemoglobina, o VCM e a contagem plaquetária são compatíveis com o que se vê na distensão, ou se existe alguma característica artefatual que possa invalidá-los. Quando as contagens e a distensão são incompatíveis, deve-se inspecionar a amostra sanguínea, repetir as contagens e, se necessário, fazer nova distensão. Tais discrepâncias podem ter como causa: 1) homogeneização incompleta ou coagulação parcial da amostra, 2) amostra insuficiente, resultando na aspiração de volume inadequado pelo equipamento, ou 3) a utilização de diferentes amostras sanguíneas para a distensão e para as contagens. Excluídos estes erros técnicos, a discrepância pode resultar de uma anormalidade da amostra, como hiperlipidemia ou presença de crioaglutinina. Suspeita-se de hiperlipidemia quando há eritrócitos de contornos borrados, e eritrócitos aglutinados sugerem crioaglutinina. ${ }^{6,10}$

A padronização de procedimentos no laboratório clínico ambulatorial e hospitalar, particularmente no setor de hematologia, é de fundamental importância para a obtenção da exatidão e da precisão dos resultados. O objetivo da padronização é eliminar, ou, pelo menos, reduzir a ambiguidade e a subjetividade inerentes aos procedimentos adotados na rotina laboratorial ambulatorial e hospitalar. A padronização começa com o preparo do paciente através das instruções a ele fornecidas pelo laboratório, no sentido de que o material seja coletado, armazenado e transportado da forma mais adequada e correta possível, seguida do processamento, análise, interpretação e digitação do laudo. ${ }^{3,8}$

$\mathrm{O}$ presente trabalho tem como objetivo assegurar se diferentes tempos de armazenamento da amostra na temperatura ambiente e diferentes tempos de armazenamento da amostra refrigerada a $4^{\circ} \mathrm{C}$ apresentam alterações significativas nos parâmetros do hemograma realizado com amostras de sangue total com EDTA, sem alterações hematológicas diagnosticadas, obtido de pacientes sem clínica de doença, sendo considerados indivíduos com valores de referências hematológicos normais. Com isso, pretende-se minimizar possíveis erros pré-analíticos, assim como comparar os resultados obtidos na pesquisa com o tempo limite de estocagem da amostra de sangue total preconizada pela literatura e verificar se esta informação pode ser aplicada na prática laboratorial.

\section{Casuística e Métodos}

As amostras sanguíneas para a realização dos hemogramas foram coletadas de vinte indivíduos adultos de ambos os sexos, sendo dez homens e dez mulheres, com faixa etária entre 21 e 48 anos, não fumantes, sem alterações hematológicas diagnosticadas, sem clínica de doença, sendo consi- 
derados indivíduos com valores de referências hematológicos normais, que, após terem manifestado seu desejo de doar sangue, foram informados do estudo e, sob seu consentimento, foram coletados em duplicatas para cada participante $4 \mathrm{ml} \mathrm{de}$ sangue com tubos a vácuo (Vacutainer ${ }^{\circledR}$ ) com EDTA dipotássico, através de punção venosa.

As amostras de sangue periférico coletadas em EDTA foram processadas em um contador Sysmex ${ }^{\circledR}$ XT2000i após homogeneização de 15 minutos.

Os parâmetros do hemograma analisados pelo contador hematológico foram: contagem total de eritrócitos (RBC), concentração de hemoglobina (HB), hematócrito, volume corpuscular médio (VCM), hemoglobina corpuscular média (HCM), concentração da hemoglobina corpuscular média (CHCM), índice de variação do tamanho dos eritrócitos (RDW), contagem total de leucócitos (WBC) e contagem de plaquetas (PLQ).

Das quarenta amostras obtidas, vinte foram armazenadas em temperatura ambiente $\left(25^{\circ} \mathrm{C}\right)$ e as outras vinte foram armazenadas a $4^{\circ} \mathrm{C}$. A temperatura refrigerada foi controlada duas vezes ao dia (manhã e tarde).

As amostras sanguíneas foram submetidas a diferentes tempos de armazenamento após coleta; tanto as vinte amostras armazenadas em temperatura ambiente $\left(25^{\circ} \mathrm{C}\right)$ quanto as vinte amostras armazenadas em temperatura refrigerada $\left(4^{\circ} \mathrm{C}\right)$ foram processadas no contador hematológico nos tempos 1, 3, 8, 12, 24, 36, 48 e 72 horas após a coleta.

\section{Análise estatística}

Os resultados foram avaliados através de análise estatística descritiva e comparação de médias através de análise de variância (ANOVA), considerando intervalo de confiança de $95 \%$ e nível estatístico de $5 \%$ para rejeição da hipótese de nulidade.

\section{Resultados}

No tempo de uma hora de armazenamento, tanto as amostras submetidas a refrigeração a $4^{\circ} \mathrm{C}$ quanto as submetidas em temperatura ambiente obtiveram os mesmos valores médios na contagem de eritrócitos $\left(4,86 \times 10^{12} / \mathrm{L}\right)$. Na temperatura ambiente, as médias variaram em torno de 4,86 a 4,90 $\times 10^{12} / \mathrm{L}$, enquanto no ambiente refrigerado a média da contagem de eritrócitos obteve um pico em torno de três horas de armazenamento e uma queda no valor médio em torno de 72 horas. A contagem de eritrócitos variou no decorrer dos tempos (Figura 1). No entanto, não houve variação estatística significante para ambas as temperaturas de armazenamento.

Assim como a contagem dos eritrócitos, a média da dosagem de hemoglobina, no tempo de uma hora de armazenamento, obteve os mesmos valores médios $(14,89 \mathrm{~g} / \mathrm{dL})$ entre as amostras submetidas a refrigeração a $4^{\circ} \mathrm{C}$ e as submetidas a temperatura ambiente. Houve uma queda no valor médio da hemoglobina em ambas as temperaturas nas três

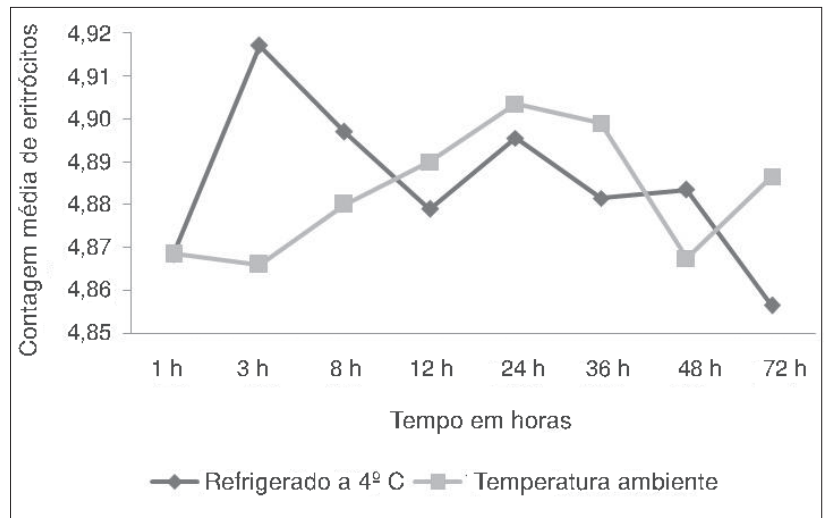

Figura 1. Perfil médio de contagem de eritrócitos

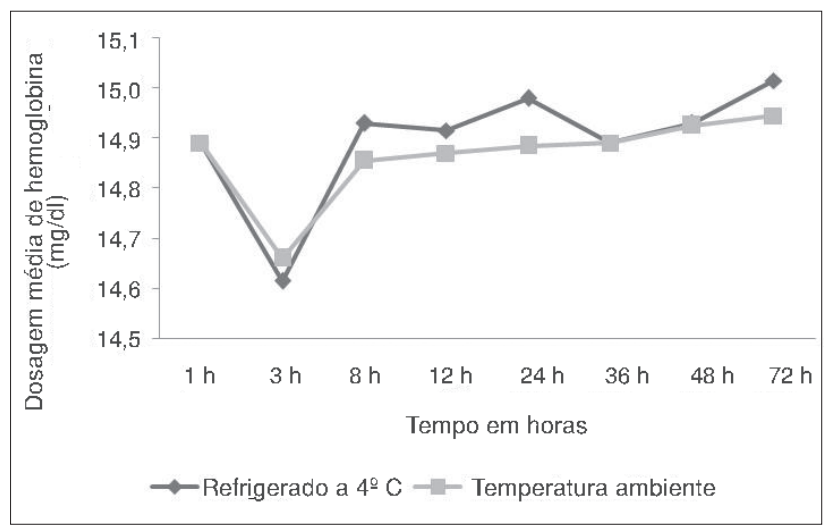

Figura 2. Perfil médio da dosagem de hemoglobina

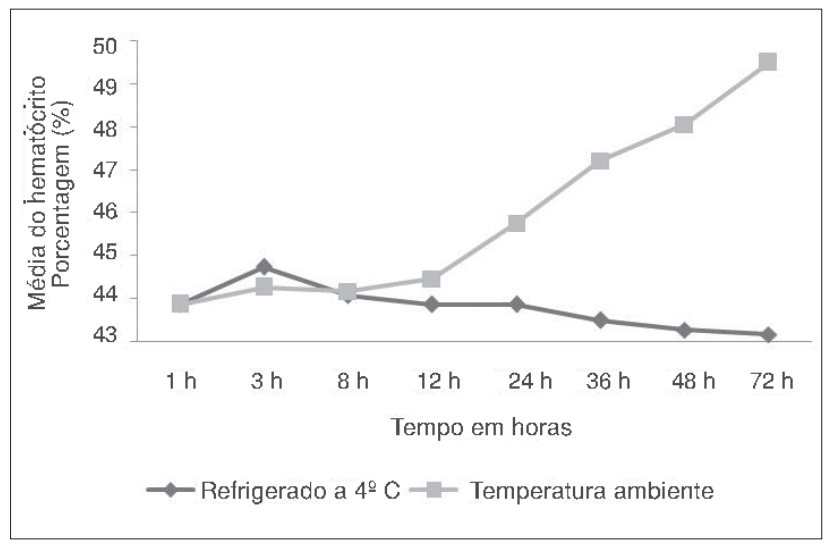

Figura 3. Perfil médio do hematócrito

horas de armazenamento; nos demais tempos houve pouca variação entre as médias, o que também resultou na não variação estatística para ambas as temperaturas (Figura 2).

Os resultados mostraram que a média do hematócrito variou de 43,86 a $49,50 \%$ nas amostras que permaneceram em temperatura ambiente no decorrer dos tempos. Até 12 horas de armazenamento, a média permaneceu homogênea, depois elevou-se, o que resultou numa diferença estatística 


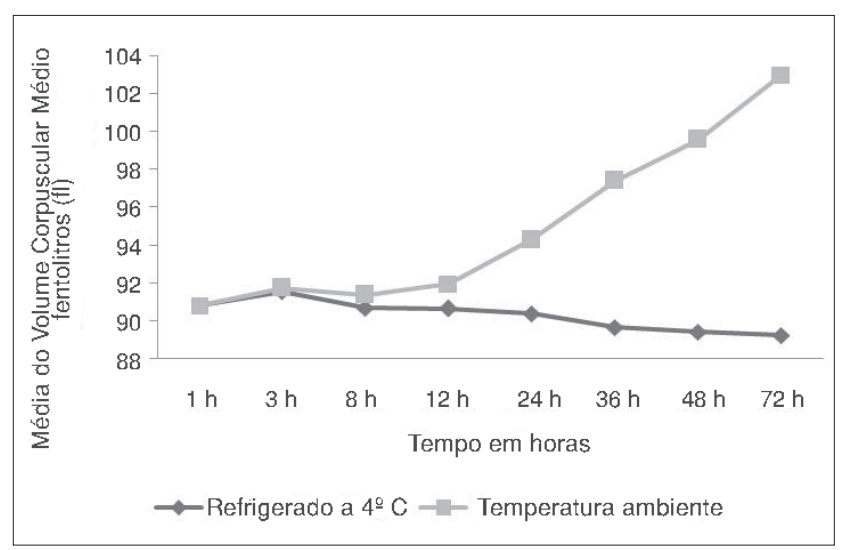

Figura 4. Perfil médio do Volume Corpuscular Médio (VCM)

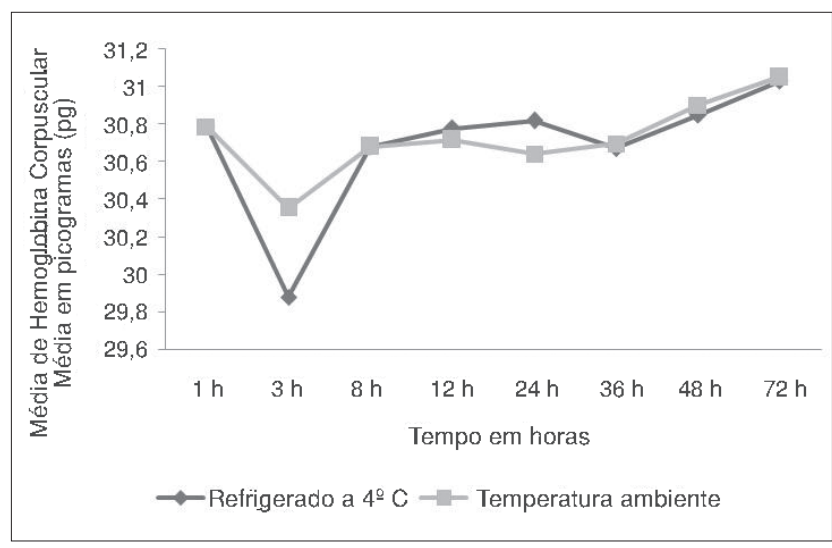

Figura 5. Perfil médio da Hemoglobina Corpuscular Média

significante. O mesmo não ocorreu para amostras em temperatura refrigerada, que tiveram uma variação das médias de 43, 17 a 44,74\% (Figura 3).

Os resultados dos valores médios encontrados para o volume corpuscular médio (VCM), dentro da primeira hora de armazenamento, foi igual para ambas as temperaturas de armazenamento (90,79 fL). No entanto, o perfil médio do VCM para amostras mantidas na temperatura ambiente apresentou uma variação de 90,79 a 103,01 fL, o que resultou numa variação estatística significativa. É importante observar que os valores médios do VCM começaram a subir após 12 horas, assim como também aconteceu com o hematócrito. $\mathrm{O}$ mesmo não ocorreu para amostras refrigeradas a $4^{\circ} \mathrm{C}$, como demonstrado na Figura 4.

O perfil médio da hemoglobina corpuscular média mostrou o mesmo valor na primeira hora de armazenamento, para ambas as temperaturas, de $30,78 \mathrm{pg}$, enquanto nas três horas houve uma queda dos valores médios, sendo maior para a amostra refrigerada $(29,8 \mathrm{pg})$. No entanto, no decorrer do tempo, as amostras mantiveram seus valores médios homogêneos, não apresentando diferença estatisticamente significante para ambas as temperaturas de armazenamento (Figura 5).

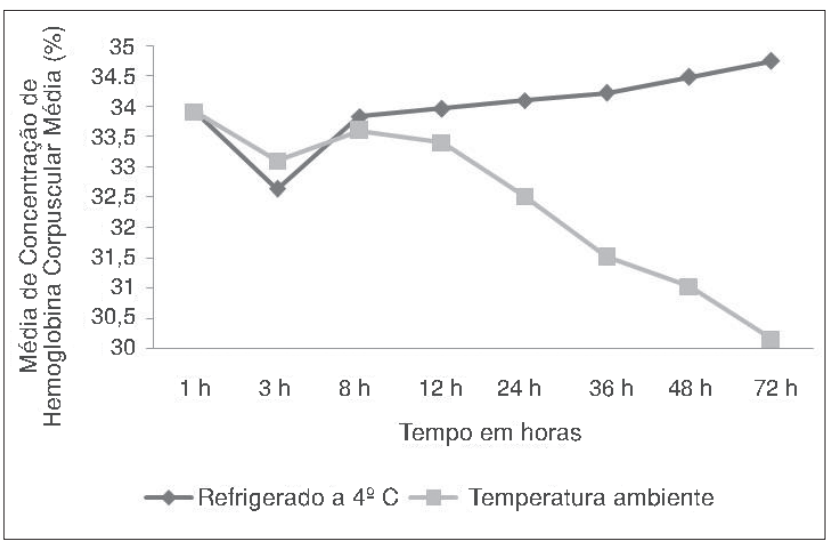

Figura 6. Perfíl médio da $\mathrm{CHCM}$

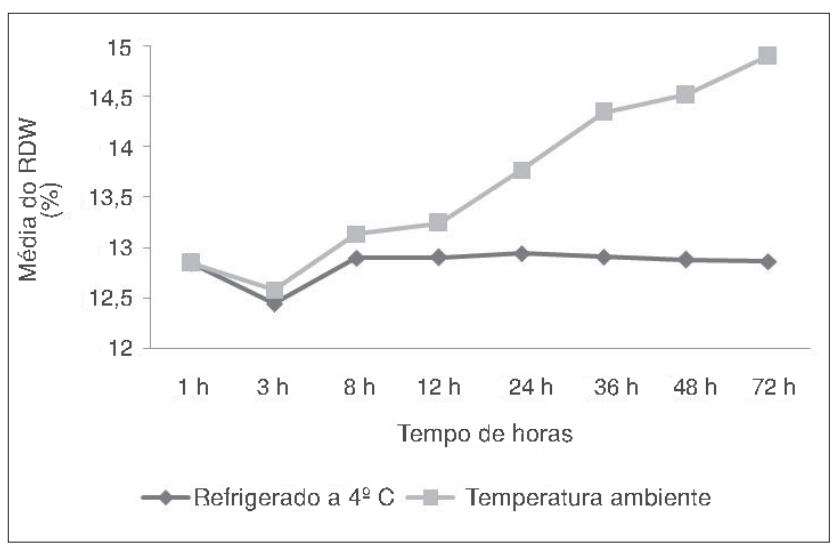

Figura 7. Perfil médio do RDW

Entre todos os resultados apresentados, a variação das médias da concentração de hemoglobina corpuscular média foi que apresentou diferenças estatisticamente significantes tanto para as amostras armazenadas a temperaturas ambiente quanto para as refrigeradas. No entanto, a variação foi maior para amostra armazenada em temperatura ambiente, que foi de 30,15 a $33,9 \%$; já para refrigeração a $4^{\circ} \mathrm{C}$ foi de 32,6 a $34,7 \%$. Lembrando que, na temperatura ambiente, além de ocorrer uma diferença estatística, também precisa se atentar para a diferença clínica, já que valores de CHCM abaixo de $32 \%$ são clinicamente importantes. E, mais uma vez, os valores começam a tornar-se discrepantes após as 12 horas (Figura 6).

Os resultados apresentados para os valores médios do RDW foram estatisticamente significantes para as amostras mantidas na temperatura ambiente, tornando-se discrepantes esses valores após 12 horas, mas é acima de 36 horas que o valor médio ultrapassa os limites de referências clinicamente significantes. O mesmo não ocorreu para amostras armazenadas em refrigeração a $4^{\circ} \mathrm{C}$ (Figura 7).

Com relação aos resultados apresentados para contagem total de leucócitos, embora tenha havido uma variação das médias após 24 horas para ambas as temperaturas de armazenamentos, não houve diferença estatística significante. 
Na primeira hora de armazenamento, a média foi igual para ambas as temperaturas (6.663 leucócitos $\left./ \mathrm{mm}^{3}\right)$. A variação das médias para amostras mantidas na temperatura ambiente foi de 6.476 a 6.713 leucócitos $/ \mathrm{mm}^{3}$; já para temperatura refrigerada foram de 6.195 a 6.695 leucócitos $/ \mathrm{mm}^{3}$ (Figura 8).

Entre todos os resultados apresentados, a contagem de plaquetas foi a que maior apresentou variação entre suas médias. Na temperatura ambiente, a média variou de 188,350 a $254,250 \times 10^{9} / \mathrm{L}$. Já para temperatura refrigerada, a média variou de 203,550 a 260,900 x10\%/L. Houve diferença estatística significante para ambas as temperaturas, com uma atenção maior para o tempo de armazenamento de 72 horas, que também foi clinicamente significante para cinco indivíduos, pois estes tiveram seus valores de plaquetas menores do que o de referência.

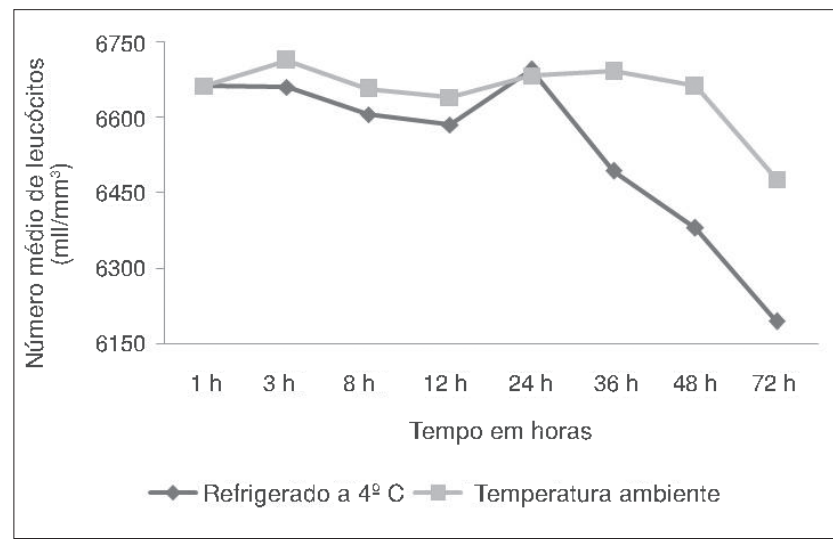

Figura 8. Perfil médio da contagem de leucócitos totais

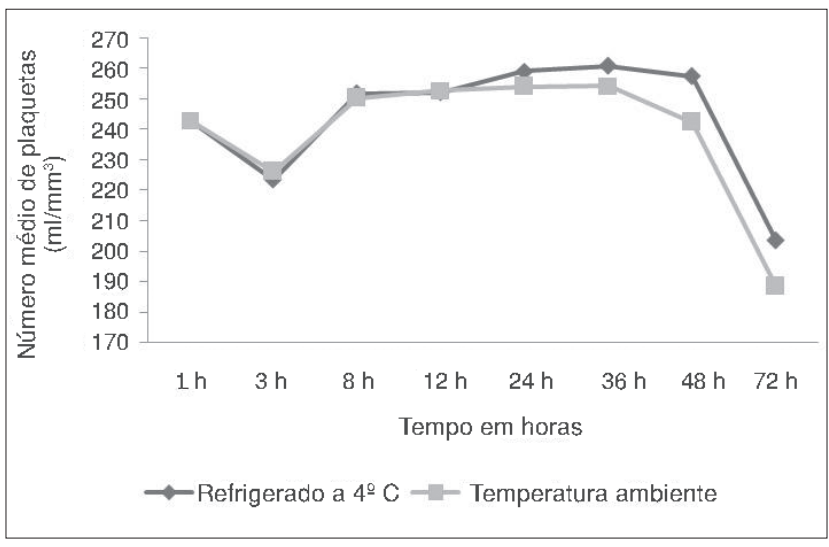

Figura 9. Perfil médio da contagem de plaquetas

\section{Discussão}

De acordo com os resultados apresentados, a contagem dos eritrócitos, tanto na temperatura ambiente quanto na refrigerada a $4^{\circ} \mathrm{C}$, pode-se observar que não houve diferenças significativas nos períodos avaliados. No entanto, eritrócitos normais são pouco afetados quando conservados em temperatura ambiente por até seis horas. Períodos mais longos do que esse podem causar crenação e esferação. Com excesso de EDTA, a crenação, em poucas horas, já é acentuada. ${ }^{2,6}$

Todas as alterações citadas são retardadas, mas não abolidas, em sangue conservado a $4^{\circ} \mathrm{C}$. As alterações são mais precoces quando submetidos à conservação sob temperaturas mais altas $\left(18\right.$ a $\left.25^{\circ} \mathrm{C}\right)$. Nesse caso, os eritrócitos incham, de modo que o hematócrito e o volume corpuscular médio (VCM) aumentam, as contagens de plaquetas e leucócitos diminuem gradualmente., ${ }^{2,9}$

Data de 1929 a descrição do hematócrito por Wintrobe, que se dá pela separação entre glóbulos vermelhos e plasma por centrifugação. Confrontando resultados do hematócrito com a dosagem de hemoglobina e a contagem de eritrócitos em paciente anêmicos, este autor pôde idealizar as clássicas formulações dos dados hematológicos, VCM, HCM e CHCM, em 1932, e classificar morfologicamente as anemias em 1934. O VCM é o índice mais importante por automação, pois é a base para classificação morfológica das anemias. Porém, por trata-se de média, o VCM normal não isenta a presença de micrócitos e/ou macrócitos circulantes. ${ }^{12,13}$

O hematócrito e o HCM são índices calculados pelo computador a partir de determinações diretas feitas pelo equipamento (eritrócitos x VCM, hemoglobina/eritrócitos, respectivamente). ${ }^{12,13}$

A CHCM, embora seja um índice derivado (hemoglobina/hematócrito ou HCM/VCM) por variar pouco nas populações eritroides, é internacionalmente utilizada para a avaliação dos resultados dos aparelhos de automação. Resultados de CHCM entre 30\% e 36\% não são notados na microscopia. Valores baixos, sem causa óbvia justificam a passagem da amostra em aparelhos de automação alternativa. ${ }^{12}$

Em sangues conservados a $4^{\circ} \mathrm{C}$, não há mudança significativa no hematócrito e no VCM nas primeiras 24 horas. As demais alterações também são mais lentas a essa temperatura, de modo que o sangue pode ser guardado de um dia para o outro no refrigerador, desde que não sofra congelação. ${ }^{2,6,14}$

Neste trabalho foram observadas alterações significativas nos valores de hematócrito, VCM e CHCM dos resultados na temperatura ambiente e o mesmo ocorreu com a CHCM na temperatura refrigerada. Quanto aos resultados do HCM, não foram observadas diferenças significativas em ambas as temperaturas avaliadas ao longo dos períodos determinados.

Amostras de sangue conservadas em temperatura ambiente por tempo prolongado (mais de 12 horas) ou em geladeira por mais de 24 horas causam elevação proporcional e indevida do VCM (e consequentemente do hematócrito) e diminuição da CHCM (indireta e mesmo a laser nos contadores Bayer). Podem apresentar hemoglobina normal e diminuição espúria da CHCM. ${ }^{11}$ 
A hemoglobina não se altera por vários dias, desde que a amostra de sangue não seja infectada, o que se nota pela turvação ou mudança de cor. Em dois a três dias, mais rapidamente em temperaturas elevadas, começa a haver hemólise, com baixa da contagem de eritrócitos e do hematócrito, e aumento da HCM e da CHCM. ${ }^{2,9}$ Isto pode ser comprovado devido ao fato de que as variações dos resultados observados em ambas as temperaturas ao longo dos períodos avaliados não foram significativas.

Conservando em temperatura ambiente, a amostra de sangue total pode ser usada até 24 horas depois da coleta e na geladeira até 48 horas, conforme tem-se verificado para a contagem de eritrócitos, leucócitos e dosagem de hemoglobina. Para as outras provas deve ser usada até duas horas após a coleta. Nos casos de anemia hemolítica, icterícia de qualquer causa, é aconselhável proceder ao exame o mais rápido possível. ${ }^{10}$

O RDW é calculado como coeficiente de variação da frequência dos volumes eritrocitários. O RDW é um uso exclusivo da tecnologia. Equivale ao grau de anisocitose, outrora obtido apenas pela morfologia eritrocitária. A notável reprodutibilidade do RDW o torna um índice de grande confiabilidade para avaliar qual o limite normal de hemoglobina de cada indivíduo. Valores de RDW alterados, mesmo para indivíduos de níveis de hemoglobina ainda normais, sugerem alteração eritroide. ${ }^{11,13}$

No presente estudo, os resultados obtidos em relação ao RDW demonstraram diferença significativa nas amostras avaliadas em temperatura ambiente, mas o mesmo não ocorreu com as amostras avaliadas em temperatura refrigerada.

Em relação à contagem total de leucócitos, apesar de não haver diferença estatística significativa, observou-se uma baixa da contagem nos períodos de 48 a 72 horas.

Contudo, independentemente do anticoagulante, distensões de sangues conservadas a temperatura ambiente, feitas até uma hora após a coleta, são difíceis de distinguir de distensões feitas imediatamente após a coleta. Após três horas, as alterações já podem ser notadas e, após 12 a 18 horas, tornam-se chamativas. Vários neutrófilos são afetados; o núcleo cora-se mais homogeneamente, os lobos nucleares separam-se, e a margem citoplasmática tornam-se franjada ou imprecisa, surgem pequenos vacúolos citoplasmáticos. Portanto, é recomendável contar leucócitos e, especialmente, plaquetas nas primeiras duas horas da coleta. A contagem de leucócitos pode diminuir muito se houver excesso de EDTA, por diluição da amostra sanguínea. As alterações degenerativas nos leucócitos afetarão muito as contagens diferenciais automatizadas, mas a conservação a $4^{\circ} \mathrm{C}$ previne significativamente esse problema ao menos até 24 horas., $2,6,14$

Os resultados observados com relação à contagem de plaquetas demonstraram diferença significativa tanto nas amostras avaliadas em temperatura ambiente quanto em temperatura refrigerada, que também é observada em outros estudos realizados, que sugerem que a diminuição de contagem de plaquetas pode ser consequência de aglutinação ou satelitismo plaquetário com amostras colhidas com EDTA (aglutinação EDTA-dependente por anticorpos $\operatorname{IgM}$ ou $\operatorname{IgG}$ que possuem maior poder de aglutinação a baixas temperaturas). ${ }^{11}$

O sangue, in vitro, tem durabilidade limitada. Conservado a mais de $20^{\circ} \mathrm{C}$, há putrefação após 48 horas. Os prazos atuais de conservação adequada para contagens eletrônicas em sangue coletado em tubo estéril, sem sofrer agitação, são $26^{\circ} \mathrm{C}$ a $37^{\circ} \mathrm{C}$ para duas a quatro horas, $08^{\circ} \mathrm{C}$ a $25^{\circ} \mathrm{C}$ para oito a 12 horas, $01^{\circ} \mathrm{C} \mathrm{a} 07^{\circ} \mathrm{C}$ para 24 a 36 horas. O laboratório deve ser informado da hora de coleta e das condições de transporte de materiais enviados. A coleta tardia, em postos de coleta afastados, após passagem do transporte diário, é possível: coleta-se o sangue, distendem-se duas lâminas (identificadas e guardadas em caixa fechada, à temperatura ambiente $-25^{\circ} \mathrm{C}$ ), e conserva-se o sangue em refrigerador até o transporte e o processamento na manhã seguinte. ${ }^{8}$

\section{Conclusões}

A partir da avaliação dos resultados obtidos neste estudo, pode se concluir que em ambas as temperaturas de estocagem (ambiente e refrigerada a $4^{\circ} \mathrm{C}$ ) é possível ocorrer alterações significativas em diversos parâmetros do hemograma. Dentre eles, os dados hematológicos, que são importantes para o auxílio na classificação morfológica das anemias. Vale lembrar que, além das alterações observadas neste trabalho, também podem ocorrer alterações na análise microscópica da morfologia celular dos leucócitos. ${ }^{2-8}$ Concluise, portanto, que os resultados dos hemogramas liberados pelo aparelho analisado podem ser satisfatórios quando realizados entre 12 a 24 horas após a coleta da amostra para a maioria dos parâmetros avaliados. Portanto, fica clara a importância de se padronizar um período para a realização do hemograma após a coleta.

\section{Abstract}

This study evaluated possible alterations in different hematologic parameters [total erythrocyte count, hematocrit, hemoglobin concentration, mean corpuscular volume (MCV), mean corpuscular hemoglobin (MCH), mean corpuscular hemoglobin concentration (MHCM), total leukocyte count and platelet count], of blood samples submitted to varied storage times at both $4^{\circ} \mathrm{C}$ and at room temperature. The analyses were performed using a Sysmex XT2000i automated hematology analyzer. Written consent was obtained from donors with no hematological disorders or clinical abnormalities and thus from individuals with apparently normal laboratory reference values for healthy adults. The results were analysed by descriptive statistics with comparisons of the means being achieved by analysis of variance (ANOVA). The means of the MCHC parameters and platelet count showed significant statistical differences for both storage temperatures. At room temperature the hematocrit, $M C V$ and red cell distribution width (RDW) readings 
also presented statistically significant differences. Therefore, it can be concluded that hemogram results performed by automated blood analyzers are satisfactory when carried out within 24 hours after drawing the blood sample for most of the parameters evaluated. Rev. Bras. Hematol. Hemoter.

Key words: Blood; blood count; storage of materials and supplies; equipment; parameters.

\section{Referências Bibliográficas}

1. Xavier R, Albuquerque G.; Barros, E. Laboratório na prática clínica: consulta rápida. $1^{\mathrm{a}} \mathrm{ed}$. Porto Alegre: Artmed, 2005; 3:61-3.

2. Lewis SM, Bain BJ, Bates I. Hematologia prática de Dacie e Lewis. 9a. Porto Alegre: Artmed, 2006.

3. Ferreira MFR, Vieira LMF, Bastos M. Garantia da qualidade do hemograma automatizado. RBAC, 2002;34(3):121-9.

4. Nascimento MLO. Significado dos resultados dos exames do eritrograma após automação laboratorial. Labor News, 155, 2005.

5. Silva PH, Hashimoto Y. Interpretação Laboratorial do Eritrograma Texto \& Atlas. São Paulo: Lovise, 1999; 1:17-23.

6. Bain BJ. Células Sanguíneas: Um guia prático. $3^{\mathrm{a}}$ ed. Porto Alegre: Artmed, 2006.

7. Carvalho WF. Técnicas médicas de hematologia e imunohematologi. $6^{a}$ ed. Belo Horizonte: COOPMED, 1994; 3:34-40; 4:41-5.

8. Failace R. Hemograma: manual de interpretação. $4^{\mathrm{a}}$ ed. Porto Alegre: Artmed, 2003; 1:14-37.

9. Cohle, Stephen D, Saleen Abdus, Makkaoui Denorah E. Efects of storage of blood on stability of hematologic parameters. Department of Pathology, Baylor College of Medicine and Methodist Hospital, Houston, Texas. ASCP, vol 76, 12 fev 1981.

10. Jannini P. Interpretação clínica do hemograma. São Paulo: Sarvier, 1978.

11. Oliveira RAG. Hemograma: como fazer e interpretar. São Paulo: LPM, 2007.

12. Failace R, Pranke P. Avaliação dos critérios de liberação direta dos resultados de hemogramas através de contadores eletrônicos. Rev. bras. hematol. hemoter. 2004; 26(3):159-66.

13. Nascimento MLP, Silva LL. Comparação da frequência de morfologias eritrocitárias adquiridas entre as avaliações por automação e por estudo morfológico. Labor News. 2006;162:16-20.

14. Ribeiro WR. Hematologia: um guia para introdução ao estudo. $1^{a}$ ed. Goiânia: Nacional, 1996.

Avaliação: Editor e dois revisores externos

Conflito de interesse: sem conflito de interesse

Recebido: 12/03/2009

Aceito após modificações: 04/08/2009 